\title{
Reliability Analysis of Automatic Transmission Based on T-S Fuzzy Fault Tree
}

\author{
Chaokai Lei*, Haitao Ji, Ning Hu \\ Shanghai University of Engineering Science, Shanghai, China \\ Email: *ishine2016@163.com
}

How to cite this paper: Lei, C.K., Ji, H.T. and $\mathrm{Hu}, \mathrm{N}$. (2018) Reliability Analysis of Automatic Transmission Based on T-S Fuzzy Fault Tree. Open Access Library Journal, 5: e4659.

https://doi.org/10.4236/oalib.1104659

Received: May 15, 2018

Accepted: June 11, 2018

Published: June 14, 2018

Copyright $\odot 2018$ by authors and Open Access Library Inc.

This work is licensed under the Creative Commons Attribution International License (CC BY 4.0).

http://creativecommons.org/licenses/by/4.0/

(c) (i) Open Access

\begin{abstract}
In order to solve the lack of automatic transmission slippage fault data, the uncertainty of the link between the source of the fault and the degree of failure, the lack of applicability of the traditional Boolean logic gate, the T-S model and fuzzy theory and the revision of the confidence index are proposed. The expert survey method was combined and the analysis method was introduced into the fault tree. The T-S model is introduced into the typical fault analysis, using the fuzzy possibility to describe the failure probability of the component. The connection between events is described with the T-S gate. The fault degree of the component is described by the fuzzy number, the model simulation is used to simulate the fault analysis, and the contribution or importance of the top event to the failure of the component is obtained. The fuzzy possibility and fault diagnosis of the top event are calculated. Without knowing the fault mechanism accurately, we can find the weak link of the system, and provide reference for automatic transmission slip fault diagnosis and maintenance.
\end{abstract}

\section{Subject Areas}

Automata

\section{Keywords}

Automatic Transmission, T-S Model, Fuzzy Fault Tree, Fault Diagnosis, Reliability Confidence Index

\section{Introduction}

Hydraulic automatic transmission is widely used in cars [1]. The automatic transmission is a complex system that combines mechanical, electronic and hydraulic components. Due to the complex structure and working principle of the 
hydraulic automatic transmission, the difficulty of fault detection is increased. The fault diagnosis carried out by an on-board diagnostic system in a modern electronically controlled automatic transmission is generally limited to the judgment of the electrical system fault. There is no clear test result for hydraulic faults that play a key role. Because of the complexity of the structure and composition of its own hydraulic system, the probability of failure is correspondingly higher. And hydraulic system faults also have diversity, uncertainty and ambiguity [2].

Fault Tree Analysis (FTA) is a method for analyzing system reliability. It has been recognized as one of the simplest, most effective, and most promising tools for reliability analysis, prediction, and design of complex systems [3]. Fault tree analysis is an effective tool for analyzing the reliability and safety of large-scale complex systems. Traditional fault tree analysis methods based on probability theory and Boolean algebra have been widely used in fault diagnosis of hydraulic systems. However, the traditional fault tree analysis method has the following deficiencies: a) The failure probability of the bottom event must be known accurately; b) The connection between the events needs to be accurately known; c) The severity of the failure cannot be described. The above three shortages make it difficult to establish and quantitatively analyze the fault tree, thus limiting the application of fault tree analysis in hydraulic system fault diagnosis. Tanaka et al. [4] introduced the fuzzy theory into the fault tree analysis for the first time in 1983, thus solving the ambiguity and uncertainty of the failure rate of the basic event in the fault tree (using fuzzy multiplication instead of the traditional logic operation, but still in and or gates logically). Yao Chengyu et al. [5] [6] put forward the T-S fuzzy fault tree model and applied them to equipment diagnosis and control equipment diagnosis, integrated navigation system and so on, and achieved good results.

The fuzzy theory has the advantages of dealing with fuzzy and inaccurate information, combining the fault tree analysis method with the fuzzy theory. It not only draws the advantages of the fault tree analysis, but also takes full account of the characteristics of the fault occurrence probability, the connection of the events and the fuzziness of the fault degree, and it is carried out. An effective method for fault diagnosis of hydraulic system is made, so the slip fault of automatic transmission is analyzed. In this paper, a fuzzy fault tree method based on T-S fuzzy fault tree is proposed for the diagnosis and analysis of automatic transmission.

\section{T-S fuzzy Fault Tree}

A new T-S fuzzy fault tree is constructed by using T-S gates instead of traditional logic AND gates. In the new fault tree, the failure probability and the degree of failure of each basic event are replaced by fuzzy numbers. Figure 1 shows the T-S fuzzy gate fault tree model. Where $x_{1}, x_{2}, x_{3}, x_{4}, x_{5}$ is basic events. Gate a and gate $b$ are logic gate. 


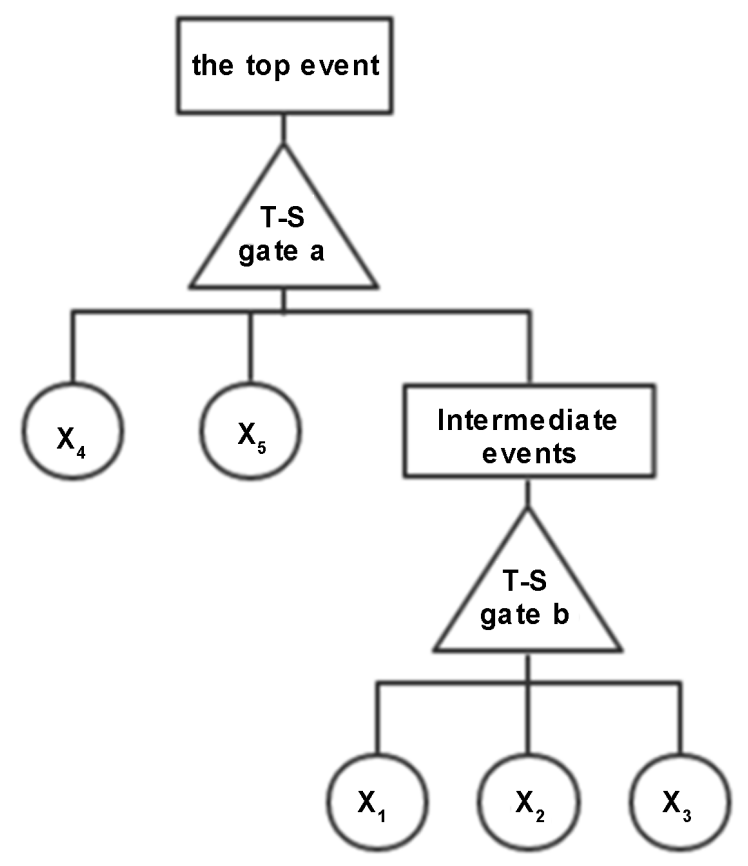

Figure 1. Fuzzy fault tree.

\subsection{Fuzzy Number}

Considering that traditional failure trees have less historical failure data for basic events in practical applications, fuzzy logic is introduced. Using fuzzy numbers to represent the failure probability of each basic event, the establishment of a fault tree is no longer dependent on a large number of failure data. In the T-S fuzzy fault tree, the degree of each fault is usually represented by the fuzzy number in the interval $[0,1]$.

The trapezoidal membership function $\mu(x)$, shown in Figure 2, is used as the membership function of fuzzy numbers.

$$
\mu(x)=\left(m_{0}, a_{l}, b_{l}, a_{r}, b_{r}\right)
$$

The membership function expression of Figure 2 as follows:

$$
\mu(x)= \begin{cases}0 & 0 \leq x \leq m_{0}-a_{l}-b_{l} \\ \frac{x-\left(m_{0}-a_{l}-b_{l}\right)}{b_{l}} & m_{0}-a_{l}-b_{l}<x \leq m_{0}-a_{l} \\ 1 & m_{0}-a_{l}<x \leq m_{0}+a_{r} \\ \frac{m+a_{r}+b_{r}-x}{b_{r}} & m_{0}+a_{r}<x \leq m_{0}+a_{r}+b_{r} \\ 0 & m_{0}+a_{r}+b_{r}<x\end{cases}
$$

where $m_{0}$ is the center of a fuzzy number support set, $a_{l}$ and $a_{r}$ is supporting radius, $b_{l}$ and $b_{r}$ is area of fuzzy.

According to Figure 2, we can see, when $a_{l}=a_{r}=0$, trapezoid membership function is a triangle membership function; when $b_{l}=b_{r}=0$ fuzzy number as a definite number. 


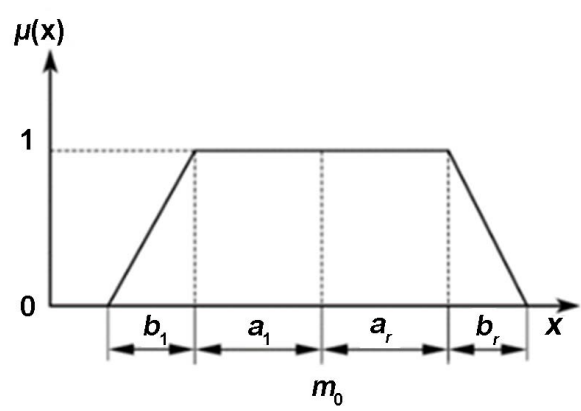

Figure 2. Membership function of fuzzy number.

\subsection{T-S Fuzzy Gate Fault Tree Algorithm}

The T-S fuzzy model is composed of a series of IF-THEN fuzzy rules. It is a nonlinear model, which is used to describe the association between events and form a T-S fuzzy gate. The rules of the model are expressed as follows [7]:

If $x_{i}(i=1,2, \cdots, n)$ is basic event variable, $y$ is superior variable, $F_{l j}(j=1,2, \cdots, n)$ is fuzzy set, and the rules is $l(l=1,2, \cdots, m)$; if $x_{1}$ is $F_{l 1}$, $x_{2}$ is $F_{l 2}, \cdots, x_{n}$ is $F_{l n}$, then $y$ is $y_{l}$. If the membership function of the fuzzy set is $\mu_{F_{i j}}\left(x_{j}\right)$, then the output of T-S model as follow:

$$
y=\prod_{j=1}^{n} \mu_{F_{l j}}\left(x_{j}\right) / \sum_{l=1}^{m} \prod_{j=1}^{n} \mu_{F_{l j}}\left(x_{j}\right) y_{l}
$$

So basic events and superior events T-S fuzzy gates are shown in Figure 3.

If the fuzzy number: $\left\{x_{1}^{1}, x_{1}^{2}, \cdots, x_{1}^{k_{1}}\right\},\left\{x_{2}^{1}, x_{2}^{2}, \cdots, x_{2}^{k_{2}}\right\}, \cdots,\left\{x_{n}^{1}, x_{n}^{2}, \cdots, x_{n}^{k_{n}}\right\}$ and $\left\{y^{1}, y^{2}, \cdots, y^{k_{y}}\right\}$ indicates the degree of failure of the bottom event and the superior event respectively. Their range of values as follow:

$$
\left\{\begin{array}{c}
0 \leq x_{1}^{2}<x_{1}^{2}<\cdots<x_{1}^{k_{1}} \leq 1 \\
0 \leq x_{2}^{1}<x_{2}^{2}<\cdots<x_{2}^{k_{2}} \leq 1 \\
\vdots \\
0 \leq x_{n}^{1}<x_{n}^{2}<\cdots<x_{n}^{k_{n}} \leq 1 \\
0 \leq y^{1}<y^{2}<\cdots<y^{k_{y}} \leq 1
\end{array}\right.
$$

The T-S fuzzy gate algorithm is described as follows:

The rules is $l(l=1,2, \cdots, m)$; if $x_{1}$ is $x_{1}^{i_{1}}, x_{2}$ is $x_{2}^{i_{2}}, \cdots, x_{n}$ is $x_{n}^{i_{n}}$, then the probability, $y$ is $y^{1}$, is $P^{l}\left(y^{1}\right)$, the probability, $y$ is $y^{2}$, is $P^{l}\left(y^{2}\right), \cdots$, the probability, $y$ is $y^{k_{y}}$, is $P^{l}\left(y^{k_{y}}\right)$. Where $i_{1}=1,2, \cdots, k_{1}, i_{2}=1,2, \cdots, k_{2}, \cdots$, $i_{n}=1,2, \cdots, k_{n}$. The total number of rules is $m$, we can get the equation of $m$ :

$$
m=\prod_{i=1}^{n} k_{i}
$$

Assuming that the degree of failure of a basic event is $P\left(x_{1}^{i_{1}}\right), P\left(x_{2}^{i_{2}}\right), \cdots, P\left(x_{n}^{i_{n}}\right)$. Then the possibility of the rules $l(l=1,2, \cdots, m)$ execution as follows:

$$
P_{0}^{l}=P\left(x_{1}^{i_{1}}\right) P\left(x_{2}^{i_{2}}\right) \cdots P\left(x_{n}^{i_{n}}\right)
$$

Therefore, the ambiguity of the superior incident is: 


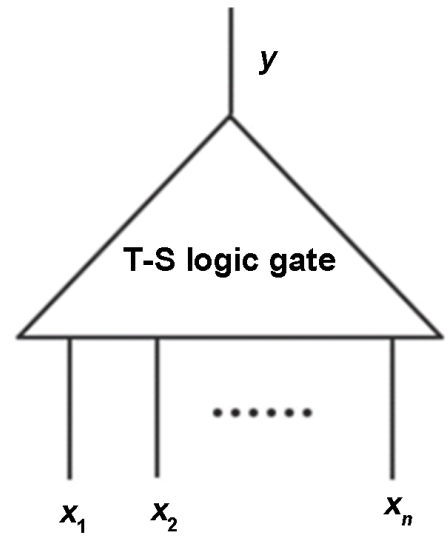

Figure 3. T-S logic gate.

$$
\left\{\begin{array}{c}
P\left(y^{1}\right)=\sum_{l=1}^{m} P_{0}^{l} P^{l}\left(y^{1}\right) \\
P\left(y^{2}\right)=\sum_{l=1}^{m} P_{0}^{l} P^{l}\left(y^{2}\right) \\
\vdots \\
P\left(y^{k_{y}}\right)=\sum_{l=1}^{m} P_{0}^{l} P^{l}\left(y^{k_{y}}\right)
\end{array}\right.
$$

If the $x_{i}(i=1,2, \cdots, n)$ fault level is $x^{\prime}=\left\{x_{1}^{\prime}, x_{2}^{\prime}, \cdots, x_{n}^{\prime}\right\}$. According to the T-S fuzzy model, the fuzzy possibility of the fault level of the upper event can be calculated as follows:

$$
\left\{\begin{array}{c}
P\left(y^{1}\right)=\sum_{l=1}^{m} \beta_{l}^{*}\left(x^{\prime}\right) P^{l}\left(y^{1}\right) \\
P\left(y^{2}\right)=\sum_{l=1}^{m} \beta_{l}^{*}\left(x^{\prime}\right) P^{l}\left(y^{2}\right) \\
\vdots \\
P\left(y^{k_{y}}\right)=\sum_{l=1}^{m} \beta_{l}^{*}\left(x^{\prime}\right) P^{l}\left(y^{k_{y}}\right)
\end{array}\right.
$$

where

$$
\beta_{l}^{*}\left(x^{\prime}\right)=\prod_{j=1}^{n} \mu_{x_{j}}^{i j}\left(x_{j}^{\prime}\right) / \sum_{i=1}^{m} \prod_{j=1}^{n} \mu_{x_{j}}^{i j}\left(x_{j}^{\prime}\right)
$$

Additionally, $\mu_{x_{j}}^{i j}\left(x_{j}^{\prime}\right)$ is the degree of membership of the fuzzy set corresponding to the fault status of the $j$ component in the 1 rule.

Therefore, taking Figure 1 as an example, if the fuzzy possibility of the degree of failure of the basic event is known, according to the T-S gate rule, the fuzzy possibility of the failure degree of the upper event can be estimated using formulas and formulas, respectively.

\subsection{T-S Fuzzy Importance}

The T-S fuzzy importance degree 1 is the contribution of the failure of the minimum cut set of a component or system to the occurrence probability of the top 
event. It is a function of the time. The reliability parameters of the component and the system structure are widely used in practice [8]. The fuzzy subset of the failure probability of the known component $x_{j}$ fault status $x_{j}^{i j}(j=1,2, \cdots, n)$ is $\tilde{P}_{x_{j}^{i j}}$, It's membership function is $\mu_{\tilde{P}_{x_{j}}}$; The fuzzy subset of the failure probability of the top event $T$ fault status $T_{q}$ is $\tilde{P}\left(\tilde{P}_{x_{1}^{1}}, \tilde{P}_{x_{2}^{i 2}}, \cdots, \tilde{P}_{x_{n}^{i n}}\right)$, where $\left(i_{1}=1,2, \cdots, k_{1}, i_{2}=1,2, \cdots, k_{2}, \cdots, i_{n}=1,2, \cdots, k_{n}\right)$, It's membership function is $\mu_{\tilde{P}_{i j}}$.

Definition: The fuzzy subset of the failure probability of component $x_{j}$ with failure status $x_{j}^{i j}(j=1,2, \cdots, n)$ is $\tilde{P}_{x_{j}^{i j}}$. It's T-S fuzzy importance for the system top event $\mathrm{T}$ is obtained by following equation:

$$
\begin{aligned}
I_{T_{q}}^{F u}\left(x_{j}^{i j}\right)= & E\left[P\left(T_{q}, \tilde{P}_{x_{j}^{i j}}=1\right)-P\left(T_{q}, \tilde{P}_{x_{j}^{i j}}=0\right)\right] \\
& =\frac{\int_{0}^{1} x \mu_{\tilde{P}_{x_{j},}, T_{q}} \mathrm{~d} x}{\int_{0}^{1} \mu_{\tilde{P}_{x_{j}, T_{q}}} \mathrm{~d} x}-\frac{\int_{0}^{1} x \mu_{\tilde{P}_{x_{j}}, 0} \mathrm{~d} x}{\int_{0}^{1} \mu_{\tilde{P}_{x_{j}, 0}} \mathrm{~d} x}
\end{aligned}
$$

where $P\left(T_{q}, \tilde{P}_{x_{j}^{i j}}=1\right)$ indicate fuzzy subset, when $\tilde{P}_{x_{j}^{i j}}$ is 1 , The probability of failure of its top event T.P $P\left(T_{q}, \tilde{P}_{x_{j}^{i j}}=0\right)$ indicate fuzzy subset, when $\tilde{P}_{x_{j}^{i j}}$ is 0 , The probability of failure of its top event $T$. Combining Equations (6) and (7) with 0 and 1 instead of $\tilde{P}_{x_{j}^{i j}}$, the two integral terms represent the center-of-gravity values of the fuzzy subset of the probability of failure of the system top event $T$ failure degree $T_{q}$ when $\tilde{P}_{x_{j}^{i j}}$ is 0 and 1 , respectively.

Definition: The following formula is expressed T-S fuzzy importance of basic events:

$$
I_{T_{q}}^{F u}\left(x_{j}\right)=\sum_{i j=1}^{k_{j}^{\prime}} I_{T_{q}}^{F u}\left(x_{j}^{i j}\right) / k_{j}^{\prime}
$$

where, $k_{j}^{\prime}$ indicate the number of non-zero fault conditions for the $j$ part. If the fault status fuzzy number is represented by $(0,0.5,1)$, then $k_{j}^{\prime}$ is $2 . I_{T_{q}}^{F u}\left(x_{j}\right)$ is the influence of each fault state on the average fault state of the system during the change of component fault status from 0 to 1 .

\section{T-S Fuzzy Fault Tree Analysis Example}

\subsection{Hydraulic Automatic Transmission T-S Fuzzy Fault Tree}

Establish T-S fuzzy fault tree [9] [10] as shown in Figure 4, $x_{1}, x_{2}, \cdots, x_{16}$ is basic events, $\mathrm{T}$ is top event, $y_{1}, y_{2}, y_{3}$ is intermediate events. According to the actual fault condition, suppose that there are three kinds of states in the degree of failure of the basic fault and intermediate event of the fuzzy fault tree of the automatic transmission T-S (Table 1): no fault, minor fault, and complete fault, which are $(0,0.5,1)$, respectively. The parameter is $a_{l}=a_{r}=0.2, b_{l}=b_{r}=0.3$.

T-S fuzzy gate rule algorithm can be obtained from expert experience and historical data in Tables 2-4. In Tables 2-4, each line represents a fuzzy rule, for example, the second line in Table 2 represents the rule. The degree of failure $x_{1}$ is $0, x_{2}$ is $0, x_{3}$ is $0, x_{4}$ is $0, x_{5}$ is 0.5 , then the possibility of $y_{1}$, when its degree of fault is $(0,0.5,1)$, is $(0.3,0.4,0.3)$. 


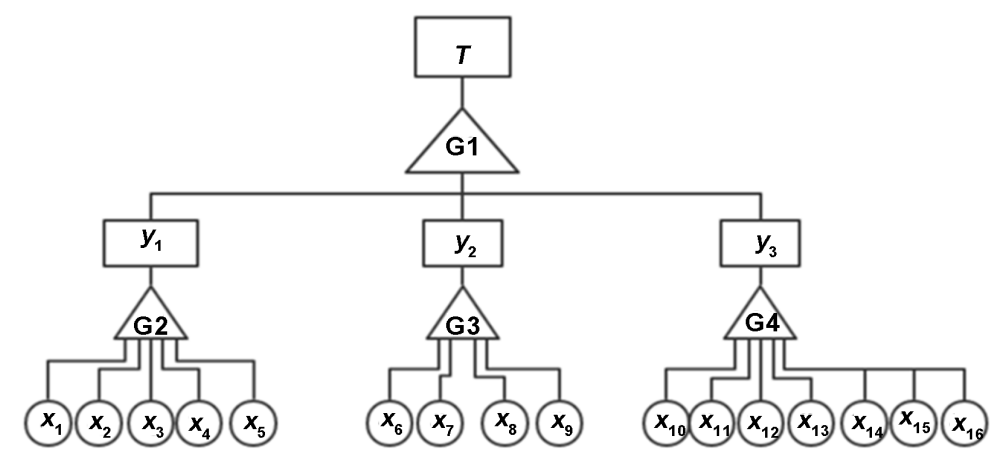

Figure 4. T-S fuzzy fault tree of hydraulic automatic transmission.

Table 1. Names of each events in the T-S fuzzy fault tree of an automatic transmission.

\begin{tabular}{cccc}
\hline $\begin{array}{c}\text { Event } \\
\text { code }\end{array}$ & Events name & $\begin{array}{c}\text { Event } \\
\text { code }\end{array}$ & Event name \\
\hline$T$ & Automatic transmission slip & $x_{7}$ & Quality deterioration of hydraulic oil \\
$y_{1}$ & Mechanical wear & $x_{8}$ & Oil pipe depression \\
$y_{2}$ & Oil problem & $x_{9}$ & Type of oil is wrong \\
$y_{3}$ & Oil leaking & $x_{10}$ & Improper adjustment of throttle position sensor \\
$x_{1}$ & Friction disc wear of clutch & $x_{11}$ & Seal ring damage of clutch piston \\
$x_{2}$ & Friction disc wear of brake & $x_{12}$ & Damage of piston seal ring of brake \\
$x_{3}$ & Wear and burn of brake belt & $x_{13}$ & Damage of piston seal ring of shock absorber \\
$x_{4}$ & Oil pump wear & $x_{14}$ & Filter blockage \\
$x_{5}$ & Unidirectional clutch skidding & $x_{15}$ & Main oil road leak \\
$x_{6}$ & Abnormal hydraulic oil surface & $x_{16}$ & Main pressure valve problem \\
\hline
\end{tabular}

Table 2. T-S fuzzy gate G2.

\begin{tabular}{|c|c|c|c|c|c|c|c|c|}
\hline \multirow{2}{*}{ Rule } & & \multirow{2}{*}{$x_{2}$} & \multirow{2}{*}{$x_{3}$} & \multirow{2}{*}{$x_{4}$} & \multirow{2}{*}{$x_{5}$} & \multicolumn{3}{|c|}{$y_{1}$} \\
\hline & & & & & & 0 & 0.5 & 1 \\
\hline 1 & 0 & 0 & 0 & 0 & 0 & 1 & 0 & 0 \\
\hline 2 & 0 & 0 & 0 & 0 & 0.5 & 0.3 & 0.4 & 0.3 \\
\hline 3 & 0 & 0 & 0 & 0 & 1 & 0 & 0.2 & 0.8 \\
\hline 4 & 0 & 0 & 0 & 0.5 & 0 & 0.2 & 0.5 & 0.3 \\
\hline 5 & 0 & 0 & 0 & 0.5 & 0.5 & 0.1 & 0.4 & 0.5 \\
\hline 6 & 0 & 0 & 0 & 0.5 & 1 & 0 & 0.1 & 0.9 \\
\hline 7 & 0 & 0 & 0 & 1 & 0 & 0 & 0.3 & 0.7 \\
\hline 8 & 0 & 0 & 0 & 1 & 0.5 & 0 & 0.1 & 0.9 \\
\hline 9 & 0 & 0 & 0 & 1 & 1 & 0 & 0 & 1 \\
\hline 10 & 0 & 0 & 0.5 & 0 & 0 & 0.2 & 0.5 & 0.3 \\
\hline 11 & 0 & 0 & 0.5 & 0 & 0.5 & 0.2 & 0.6 & 0.2 \\
\hline 12 & 0 & 0 & 0.5 & 0 & 1 & 0 & 0.1 & 0.9 \\
\hline 13 & 0 & 0 & 0.5 & 0.5 & 0 & 0.1 & 0.7 & 0.2 \\
\hline 14 & 0 & 0 & 0.5 & 1 & 0.5 & 0 & 0 & 1 \\
\hline 15 & 0 & 0 & 1 & 0 & 0 & 0.2 & 0.5 & 0.3 \\
\hline 16 & 0 & 0 & 1 & 0 & 0.5 & 0.1 & 0.8 & 0.2 \\
\hline$\vdots$ & $\vdots$ & $\vdots$ & $\vdots$ & $\vdots$ & $\vdots$ & $\vdots$ & $\vdots$ & $\vdots$ \\
\hline 243 & 1 & 1 & 1 & 1 & 1 & 0 & 0 & 1 \\
\hline
\end{tabular}


Table 3. T-S fuzzy gate G3.

\begin{tabular}{cccccccc}
\hline Rule & $x_{6}$ & $x_{7}$ & $x_{8}$ & $x_{9}$ & \multicolumn{3}{c}{$y_{2}$} \\
\hline 1 & 0 & 0 & 0 & 0 & 1 & 0 & 0 \\
\hline 2 & 0 & 0 & 0 & 0.5 & 0.2 & 0.5 & 0.3 \\
3 & 0 & 0 & 0 & 1 & 0 & 0.4 & 0.6 \\
4 & 0 & 0 & 0.5 & 0 & 0.2 & 0.5 & 0.3 \\
$\mathbf{5}$ & 0 & 0 & 0.5 & 0.5 & 0.1 & 0.4 & 0.5 \\
$\mathbf{6}$ & 0 & 0 & 0.5 & 1 & 0 & 0.1 & 0.9 \\
7 & 0 & 0 & 1 & 0 & 0 & 0.3 & 0.7 \\
$\mathbf{8}$ & 0 & 0 & 1 & 0.5 & 0 & 0.1 & 0.9 \\
9 & 0 & 0 & 1 & 1 & 0 & 0 & 1 \\
10 & 0 & 0.5 & 0 & 0 & 0.2 & 0.5 & 0.3 \\
11 & 0 & 0.5 & 0 & 0.5 & 0.2 & 0.6 & 0.2 \\
12 & 0 & 0.5 & 0 & 1 & 0 & 0.1 & 0.9 \\
$\vdots$ & $\vdots$ & $\vdots$ & $\vdots$ & $\vdots$ & $\vdots$ & $\vdots$ & $\vdots$ \\
81 & 1 & 1 & 1 & 1 & 0 & 0 & 1 \\
\hline
\end{tabular}

Table 4. T-S fuzzy gate G1.

\begin{tabular}{ccccccc}
\hline Rule & $y_{1}$ & $y_{2}$ & $y_{3}$ & \multicolumn{3}{c}{$T$} \\
\cline { 5 - 6 } & & & & 0 & 0.5 & 1 \\
\hline $\mathbf{2}$ & 0 & 0 & 0 & 1 & 0 & 0 \\
$\mathbf{3}$ & 0 & 0 & 0.5 & 0.2 & 0.4 & 0.6 \\
$\mathbf{4}$ & 0 & 0 & 1 & 0 & 0.2 & 0.8 \\
$\mathbf{5}$ & 0 & 0.5 & 0 & 0.1 & 0.5 & 0.4 \\
$\mathbf{6}$ & 0 & 0.5 & 0.5 & 0 & 0.4 & 0.6 \\
$\mathbf{7}$ & 0 & 0.5 & 1 & 0 & 0.1 & 0.9 \\
$\mathbf{8}$ & 0 & 1 & 0 & 0 & 0.3 & 0.7 \\
$\mathbf{9}$ & 0 & 1 & 0.5 & 0 & 0.1 & 0.9 \\
$\vdots$ & $\vdots$ & $\vdots$ & 1 & 0 & 0 & 1 \\
$\mathbf{2 7}$ & 1 & 1 & $\vdots$ & $\vdots$ & $\vdots$ & $\vdots$ \\
\hline
\end{tabular}

According to Tables 2-4, the fuzzy possibility of a superior event fault can be calculated by the fuzzy possibility or the degree of failure of the basic events, and then the fuzzy possibility of the top event can be estimated.

\subsection{Expert Investigation Method Combined with Confidence Index Correction}

In practical engineering appraisal applications, weighted average expert surveys are often used to obtain inaccurate or incomplete failure data [11] [12]. To study the application of T-S fuzzy fault tree in transmission slip diagnosis. This article 
intends to obtain the fuzzy failure probability of the basic event through the expert survey method based on the revision of expert confidence index. The data of the experts' selection, rating and experts' judgments are all taken from the literature [11]. Experts are selected according to academic qualifications, length of service and other conditions. The experts involved in the investigation come from first-line management, maintenance and design personnel. The composition of the experts is shown in Table 5. Calculation formula such as formula (11)

$$
\omega_{r}=v_{r} / \sum_{r=1}^{4}\left(m_{r} v_{r}\right)
$$

Ordinary expert survey methods generally assume that all experts have full confidence in their own judgments, but they are not practical when applied. In order to improve the accuracy of the fuzzy failure probability, this article introduces the "confidence index method" of the literature [11] to further correct the data obtained by the common expert survey method. Table 6 is the survey table of failure rates of basic events in the fault tree of the automatic transmission shift failure. The probability range is based on incomplete statistical data and is combined with personal work experience. Fill in the confidence index and select the confidence index for yourself. It is $0.1 \sim 1$.

Based on the expert survey method modified by the confidence index and using the weighted average idea, the overall evaluation process for the probability of a certain basic event by all experts is as follows.

1) If the number of experts participating in the survey is $\mathrm{m}$. There are $\mathrm{N}$ basic events. According to Table 5, the calculation weight of the ith expert is $w_{i}$, and he judges the probability of occurrence of the jth basic event as $\left[L_{i j}, R_{i j}\right]$, and the confidence index of judging himself as $K_{i j}\left(0<K_{i j} \leq 1\right)$. The confidence index is 1 , indicating that the expert has full confidence in his judgment and high credibility; and the confidence index is 0.1 , indicating that the credibility of the expert's judgment result is very low.

2) The interval of the probability interval of the expert judgment is obtained by $\Delta_{i j}=R_{i j}-L_{i j}$.

3) If $m_{i j}=\Delta_{i j} / 2$, then the contribution of the ith expert to the final cumulative result of the $j$ th basic event occurrence probability is:

$$
P_{i j}=w_{i}\left[m_{i j}-\left(1-k_{i j}\right) \Delta_{i j}, m_{i j}, m_{i j}+\left(1-k_{i j}\right) \Delta_{i j}\right]
$$

4) The probability of the occurrence of the th basic event, the final result of the confidence index correction and the $m$ expert weight accumulation, such as the follow Equation (13)

$$
p_{j}=\sum_{i=1}^{m} p_{i j}
$$

$p_{j}$ is an fuzzy number of the isosceles triangular.

According to the statistical analysis of the automatic transmission slippage fault data and the expert survey with the confidence index correction, the reliability data of the components are shown in Table 6. 
Table 5. Composition of experts.

\begin{tabular}{cccc}
\hline Rule $r$ & Number $m_{r}$ & Coefficient $V_{r}$ & Weight $w_{r}$ \\
\hline 1 & 9 & 1.0 & 0.027400 \\
2 & 18 & 0.9 & 0.024658 \\
3 & 8 & 0.8 & 0.021918 \\
4 & 7 & 0.7 & 0.019178 \\
\hline
\end{tabular}

Table 6. Fuzzy failure rate of each basic event of automatic transmission.

\begin{tabular}{|c|c|c|c|c|c|}
\hline $\begin{array}{l}\text { Event } \\
\text { code }\end{array}$ & Event name & $\begin{array}{l}\text { Fuzzy failure rate } \\
\qquad / \times 10^{-7}\end{array}$ & $\begin{array}{l}\text { Event } \\
\text { code }\end{array}$ & Event name & $\begin{array}{l}\text { Fuzzy failure rate } \\
\qquad / \times 10^{-7}\end{array}$ \\
\hline$x_{1}$ & $\begin{array}{c}\text { Automatic } \\
\text { transmission slip }\end{array}$ & $(2.20,2.75,3.09)$ & $x_{9}$ & $\begin{array}{l}\text { Quality deterioration of } \\
\text { hydraulic oil }\end{array}$ & $(1.31,1.43,1.74)$ \\
\hline$x_{2}$ & Mechanical wear & $(2.10,2.33,3.15)$ & $x_{10}$ & Oil pipe depression & $(0.25,0.56,0.74)$ \\
\hline$x_{3}$ & Oil problem & $(1.80,2.20,2.84)$ & $x_{11}$ & Type of oil is wrong & $(1.80,2.24,3.02)$ \\
\hline$x_{4}$ & Oil leaking & $(0.92,1.16,1.88)$ & $x_{12}$ & $\begin{array}{l}\text { Improper adjustment of } \\
\text { throttle position sensor }\end{array}$ & $(1.11,2.27,3.11)$ \\
\hline$x_{5}$ & $\begin{array}{l}\text { Friction disc wear } \\
\text { of clutch }\end{array}$ & $(1.58,2.18,2.78)$ & $X_{13}$ & $\begin{array}{l}\text { Seal ring damage of clutch } \\
\text { piston }\end{array}$ & $(2.25,2.53,3.11)$ \\
\hline$x_{6}$ & $\begin{array}{l}\text { Friction disc wear } \\
\text { of brake }\end{array}$ & $(4.40,5.62,6.84)$ & $x_{14}$ & $\begin{array}{l}\text { Damage of piston seal ring } \\
\text { of brake }\end{array}$ & $(2.58,2.93,3.21)$ \\
\hline$x_{7}$ & $\begin{array}{l}\text { Wear and burn of } \\
\text { brake belt }\end{array}$ & $(1.90,2.24,3.58)$ & $x_{15}$ & $\begin{array}{c}\text { Damage of piston seal ring } \\
\text { of shock absorber }\end{array}$ & $(1.62,2.23,2.82)$ \\
\hline$x_{8}$ & Oil pump wear & $(0.80,1.20,1.60)$ & $x_{16}$ & $\begin{array}{c}\text { Main pressure valve } \\
\text { problem }\end{array}$ & $(0.51,0.83,1.12)$ \\
\hline
\end{tabular}

\subsection{Fuzzy Possibility of Higher Level Events Calculated by Fuzzy Probability of Basic Event Failures}

According to Table 6, the failure rate of these components is the failure rate when the failure state is 0.5 , and the failure rate assuming that the failure level is 0.5 is equal to the failure rate when the failure degree is 1. Combining Equations (6) and (7) with MATLAB, the likelihood of an intermediate event blurring is as follows:

$$
\begin{aligned}
P\left(y_{2}=0.5\right)= & \sum_{l=1}^{81} p_{0}^{l} p^{l}\left(y_{2}=0.5\right) \\
& =p_{0}^{1} p^{1}\left(y_{2}=0.5\right)+p_{0}^{2} p^{2}\left(y_{2}=0.5\right)+\cdots+p_{0}^{81} p^{81}\left(y_{2}=0.5\right) \\
& =(4.21,5.66,6.32) \times 10^{-7} \\
P\left(y_{2}=1\right) & =\sum_{l=1}^{81} p_{0}^{l} p^{l}\left(y_{2}=1\right) \\
& =p_{0}^{1} p^{1}\left(y_{2}=1\right)+p_{0}^{2} p^{2}\left(y_{2}=1\right)+\cdots+p_{0}^{81} p^{81}\left(y_{2}=1\right) \\
& =(13.67,15.23,16.38) \times 10^{-7}
\end{aligned}
$$

Similarly, the fuzzy possibility of different states of other intermediate events can be calculated. We can know in Table 7 .

In the same way, the likelihood of the top event being calculated is as follows: 
Table 7. Fuzzy possibility of intermediate event.

\begin{tabular}{ccc}
\hline \multirow{2}{*}{ Intermediate event } & \multicolumn{2}{c}{ Probability of fuzzy fault } \\
\cline { 2 - 3 } & $0.5 / \times 10^{-7}$ & $1 / \times 10^{-7}$ \\
\hline$y_{1}$ & $(5.201,9.951,12.708)$ & $(10.056,19.452,26.132)$ \\
$y_{2}$ & $(1.629,2.141,3.225)$ & $(2.194,4.488,5.236)$ \\
$y_{3}$ & $(4.592,8.564,11.425)$ & $(8.699,15.312,19.548)$ \\
\hline
\end{tabular}

$$
\begin{gathered}
P(T=0.5)=(18.113,20.325,23.569) \times 10^{-7} \\
P(T=1)=(38.863,46.729,55.686) \times 10^{-7}
\end{gathered}
$$

The calculation results show that the probability of failure of automatic transmission slipping is the same order of magnitude as the probability of failure of each component. The possibility of failure of the T-S fuzzy fault treetop event is far greater than the possibility of failure of each component. This result is in accordance with the actual situation, which verifies the accuracy and feasibility of the T-S fuzzy fault number in the automatic transmission fault analysis process.

Take the gravity value of each event as its failure probability, and according to formula (10), obtain the T-S fuzzy importance degree when $y$ is 0.5 when component $x$ is 0.5 , as follows:

$$
I_{0.5}^{F u}\left(x_{6}^{1}\right)=E\left[P\left(0.5, \tilde{P}_{x_{6}^{1}}=1\right)-P\left(0.5, \tilde{P}_{x_{6}^{1}}=0\right)\right]=0.166
$$

Similarly, the T-S fuzzy significance of the fault states of the components of 0.5 and 1 can be obtained as shown in Table 8 .

According to Equation (11), combined with the T-S fuzzy importance of the fault states 0.5 and 1, the T-S fuzzy significance at 0.5 is obtained.

$$
I_{0.5}^{F u}\left(x_{6}\right)=\left[I_{0.5}^{F u}\left(x_{6}^{0.5}\right)+I_{0.5}^{F u}\left(x_{6}^{1}\right)\right] / 2=0.4
$$

Similarly, the T-S fuzzy importance of each component is obtained, as shown in Table 9.

Given the fuzzy subset of the failure probability of the component's fault state, it can be known from Table 9 that when the system is in a half-fault state (0.5), the importance of $x$ is greatest, which is the weak link in the process of transmission slip. Then we can get the troubleshooting sequence:

$$
x_{6}, x_{1}\left(x_{2}, x_{5}, x_{14}\right), x_{12}\left(x_{15}\right), x_{9}, x_{8}, x_{13}, x_{11}, x_{3}, x_{7}, x_{4}\left(x_{10}, x_{16}\right) \text {. }
$$

When the automatic transmission is in a complete fault state (1), the importance of each component is from large to small: $x_{2}, x_{14}, x_{1}, x_{6}, x_{13}, x_{4}, x_{15}$, $x_{3}\left(x_{10}\right), x_{8}, x_{16}, x_{11}, x_{9}, x_{12}, x_{7}, x_{5}$, It can be seen that when the system completely fails, the importance of the basic event $x_{2}, x_{14}, x_{1}, x_{6}$ is large, the impact on the top event is also the greatest. Other components also have a certain influence, but the degree of influence is small.

In summary, the analysis result of the slip fault of the automatic transmission based on the T-S fuzzy fault tree is basically in accordance with the situation on 
Table 8. T-S fuzzy importance of each component failure state.

(a)

\begin{tabular}{ccccccccccccccc}
\hline $\begin{array}{c}\text { The fuzzy } \\
\text { importance } \\
\text { of the fault state T-S }\end{array}$ & \multicolumn{2}{c}{$x_{1}$} & \multicolumn{2}{c}{$x_{2}$} & \multicolumn{2}{c}{$x_{3}$} & \multicolumn{2}{c}{$x_{4}$} & \multicolumn{2}{c}{$x_{5}$} & \multicolumn{3}{c}{$x_{6}$} \\
\cline { 2 - 12 } & 0.5 & 1 & 0.5 & 1 & 0.5 & 1 & 0.5 & 1 & 0.5 & 1 & 0.5 & 1 \\
\hline$I_{0.5}^{F u}\left(x_{j}^{i j}\right)$ & 0.41 & 0.38 & 0.35 & 0.44 & 0.34 & 0.33 & 0.26 & 0.23 & 0.35 & 0.44 & 0.36 & 0.44 \\
$I_{1}^{F_{u}}\left(x_{j}^{i j}\right)$ & 0.69 & 0.78 & 0.64 & 0.89 & 0.47 & 0.49 & 0.52 & 0.64 & 0.27 & 0.34 & 0.69 & 0.73 \\
\hline
\end{tabular}

(b)

\begin{tabular}{|c|c|c|c|c|c|c|c|c|c|c|c|c|}
\hline \multirow{2}{*}{$\begin{array}{l}\text { The fuzzy importance } \\
\text { of the fault state T-S }\end{array}$} & \multicolumn{2}{|c|}{$x_{7}$} & \multicolumn{2}{|c|}{$x_{8}$} & \multicolumn{2}{|c|}{$x_{9}$} & \multicolumn{2}{|c|}{$X_{10}$} & \multicolumn{2}{|c|}{$X_{11}$} & \multicolumn{2}{|c|}{$x_{12}$} \\
\hline & 0.5 & 1 & 0.5 & 1 & 0.5 & 1 & 0.5 & 1 & 0.5 & 1 & 0.5 & 1 \\
\hline$I_{0.5}^{F u}\left(x_{j}^{i j}\right)$ & 0.24 & 0.28 & 0.35 & 0.39 & 0.35 & 0.41 & 0.26 & 0.23 & 0.32 & 0.39 & 0.36 & 0.41 \\
\hline$I_{1}^{F u}\left(x_{j}^{i j}\right)$ & 0.33 & 0.31 & 0.45 & 0.48 & 0.32 & 0.38 & 0.52 & 0.64 & 0.39 & 0.41 & 0.29 & 0.36 \\
\hline
\end{tabular}

(c)

\begin{tabular}{ccccccccccc}
\hline \multirow{2}{*}{$\begin{array}{c}\text { The fuzzy importance } \\
\text { of the fault state T-S }\end{array}$} & \multicolumn{3}{c}{$x_{13}$} & \multicolumn{2}{c}{$x_{14}$} & & $X_{15}$ & & $X_{16}$ \\
\cline { 2 - 9 }$y$ & 0.5 & 1 & 0.5 & 1 & 0.5 & 1 & 0.5 & 1 \\
\hline$I_{0.5}^{F u}\left(x_{j}^{i j}\right)$ & 0.38 & 0.33 & 0.35 & 0.44 & 0.36 & 0.41 & 0.26 & 0.23 \\
$I_{1}^{F u}\left(x_{j}^{i j}\right)$ & 0.50 & 0.67 & 0.69 & 0.82 & 0.54 & 0.62 & 0.36 & 0.49 \\
\hline
\end{tabular}

Table 9. Importance of T-S ambiguity for each basic event.

\begin{tabular}{ccccccccc}
\hline T-S fuzzy importance & $x_{1}$ & $x_{2}$ & $x_{3}$ & $x_{4}$ & $x_{5}$ & $x_{6}$ & $x_{7}$ & $x_{8}$ \\
\hline$I_{0.5}^{F u}\left(x_{j}^{i j}\right)$ & 0.395 & 0.395 & 0.335 & 0.245 & 0.395 & 0.4 & 0.26 & 0.37 \\
$I_{1}^{F u}\left(x_{j}^{i j}\right)$ & 0.55 & 0.765 & 0.48 & 0.58 & 0.305 & 0.71 & 0.32 & 0.465 \\
\hline T-S fuzzy importance & $x_{9}$ & $x_{10}$ & $x_{11}$ & $x_{12}$ & $x_{13}$ & $X_{14}$ & $X_{15}$ & $x_{16}$ \\
\hline$I_{0.5}^{F u}\left(x_{j}^{i j}\right)$ & 0.38 & 0.245 & 0.355 & 0.39 & 0.36 & 0.395 & 0.39 & 0.245 \\
$I_{1}^{F u}\left(x_{j}^{i j}\right)$ & 0.35 & 0.48 & 0.4 & 0.325 & 0.585 & 0.755 & 0.57 & 0.425 \\
\hline
\end{tabular}

site. The level of oil level, clutch friction, filter plugging, etc. are all weak points. If there is slippage fault, it should be a key point for troubleshooting during troubleshooting, so as to reduce system failure rate and improve normal reliability operation.

\section{Conclusions}

This paper combines fuzzy logic and T-S models with traditional fault trees and proposes the application of T-S fuzzy fault trees to automatic transmission fault diagnosis. The method effectively overcomes the problems of difficulty in obtaining the failure probability. The uncertainty of the linkage between events, and the inability describes the degree of system failure in the traditional fault tree analysis. The quantitative description is more consistent with the engineering application.

Compared with the traditional fault tree model assessment method, this method can effectively exert the advantages of fuzzy logic inference, thus solving 
the problem of uncertainty of the system failure mechanism, reducing the difficulty of the construction; combining the expert's confidence in their own evaluation and correcting the parameters and the survey data to triangular fuzzy numbers can greatly improve the accuracy of the analysis using only common fault trees and closer to the real situation.

The T-S fuzzy fault tree analysis example of automatic transmission slip failure, and the expert experience and historical data with expert survey method of confidence index correction are combined, to calculate the fuzzy failure rate of the top event and to get the fuzzy importance of the basic event. Finally the impact of the weak links of system reliability is found, which can provide reference for overhaul and fault diagnosis of automatic transmissions.

\section{References}

[1] Zhao, D.X. and Qin, R. (2015) The Current Status and Development Trend of China's Automobile Transmission. Highways \& Automotive Applications, 1, 26-29.

[2] Chen, Z. and Peng, J. (2014) Fault Failure Function Analysis Method for Hydraulic Control System of Electronically Controlled Automatic Transmission. Design and Research, 41, 22-26.

[3] Chen, Y.Y. (2005) Fault Tree Analysis of FTA. Beijing Jiaotong University, Beijing.

[4] Tanaka, H., Fan, L.T., Lai, F.S., et al. (1983) Fault-Tree Analysis by Fuzzy Probability. IEEE Transactions on Reliability, 32, 453-457. https://doi.org/10.1109/TR.1983.5221727

[5] Fan, B.Q., Wang, G.H., Wei, X.P., et al. (2012) Research on Fault Diagnosis of Equipment Measurement and Control Equipment Based on T-S Fuzzy Fault Tree. Science, Technology and Engineering, 12, 7386-7390.

[6] Yao, C.Y., Lv, J., Chen, D.N., et al. (2015) Convex Model T-S Fault Tree and Importance Analysis Methods. Journal of Mechanical Engineering, 51, 184-192. (In Chinese) https://doi.org/10.3901/JME.2015.24.184

[7] Song, H., Zhang, H.Y. and Wang, X.R. (2005) Fuzzy Fault Tree Analysis Based on T-S Model. Control and Decision, No. 8, 854-859. (In Chinese)

[8] Yao, C.Y., Zhang, Y.Y., Wang, X.F., et al. (2011) Importance Analysis Method of Fuzzy Fault Tree Based on T-S Model. China Mechanical Engineering, 22, 1261-1268. (In Chinese)

[9] Cui, T.T. (2015) Fault Diagnosis of Hydraulic Automatic Transmission Based on Fuzzy Fault Tree. Wireless Internet Technology, 6, 111.

[10] Hu, N. (2014) Troubleshooting Method of Electrical Hydraulic System through the Application of Computer. Chinese Hydraulics \& Pneumatics, 204, 62-64.

[11] Zheng, J.J., Lin, C.F. and Zhao, D.A. (2011) Risk Assessment of Shield Tunnel Construction Cost Using Fuzzy Fault Tree. Chinese Journal of Geotechnical Engineering, 33, 501-508.

[12] Qi, J., Hu, X. and Gao, X. (2014) Quantitative Risk Analysis of Subsea Pipeline and Riser: An Experts' Assessment Approach Using Fuzzy Fault Tree. International Journal of Reliability and Safety, 8, 33-50. https://doi.org/10.1504/IJRS.2014.062639 